\title{
Identification of the Polyethylene Grade Most Suitable for Natural Rubber-Polyethylene Blends used for Roofing Applications
}

\author{
W.V.W.H. Wickramaarachchi, S. Walpalage and S.M. Egodage
}

\begin{abstract}
In Sri Lanka, roofing materials are manufactured with clay, metal, plastic, wood and asbestos, and each of these has its own inherent drawbacks. Asbestos due to the economic advantages it offers, is now the most widely used roofing material in the country. However, it has scientifically proven health risks. The Government of Sri Lanka has initiated action to ban the use of asbestos as a roofing material. The focus of this study is on the development of a roofing material formed of rubberthermoplastic blends containing Natural Rubber (NR) and Polyethylene (PE). Polyethylene is being currently used as a roofing material, but since it is lightweight it needs to be anchored tightly to the roof structure. Rubber being an energy absorbing material, can be incorporated into thermoplastics to make the latter more tough. Polymer blending is a current trend which is being used to develop technically advanced new materials from commonly available polymers. Polymer blends has an excellent combination of physicochemical properties of each of their parent materials. Sri Lanka exports natural rubber and thus there is a good opportunity to make value-additions to raw rubber exports. Similarly, the development of a new material will address the current problems associated with the use of asbestos as a roofing material. This study shows the most suitable grade of PE from among its most common grades such as High Density Polyethylene (HDPE), Low Density Polyethylene (LDPE) and Linear Low Density Polyethylene (LLDPE), for blending with natural rubber The best blended composition that will have standard properties of a roofing material such as tensile strength, tear strength, hardness, water absorption level, thermal conductivity etc., .is then identified.
\end{abstract}

Keywords: Natural Rubber, Polyethylene, Roofing material, Polymer blend

\section{Introduction}

Different types of roofing materials, either manufactured locally or imported, are used extensively in Sri Lanka despite their inherent drawbacks. Clay roofing is believed to be the safest and most durable roofing material among the roofing materials commonly availble in Sri Lanka, namely asbestos, plastic and metal. However, asbestos has become the most widely used roofing material due to the economic advantages it offers and also due to the easeness with which it can be installed unlike other roofing materials. It has now been found that there are scientifically proven health issues such as respiratory diseases and lung cancers associated with asbestos [1]. The Government of Sri Lanka has alreday intiated action to impose a ban on the use of asbestos as a roofing material. Therefore, the introduction of new roofing materials that are economically advantageous to the market would be timely.

Polymer blending is more cost effective than the synthesizing of a new polymer. A polymer blend will possess a combination of physicochemical properties of each of its parent materials [2]. Thermoplastic vulcanizate is a type of reactive polymer blend which gives a finely dispersed crosslinked rubber in a continuous thermoplastic matrix, and is associated with a more miscible system than a simple blend [3]. This system may provide enhanced properties expected of a roofing material including strength, medium weight, and high impact and weather resistance.

Sri Lanka which is the world's tenth largest rubber producing country produced in the year 2014 about 98,600 metric tons of natural rubber [4]. However, approximately 16,000 metric tons of this amount were exported in raw form without any value addition what so ever. Therefore, there is a good opportunity to give value addition to raw rubber by using NR in its newer applications. Polyethylene is available in the local market in large quantities. If waste

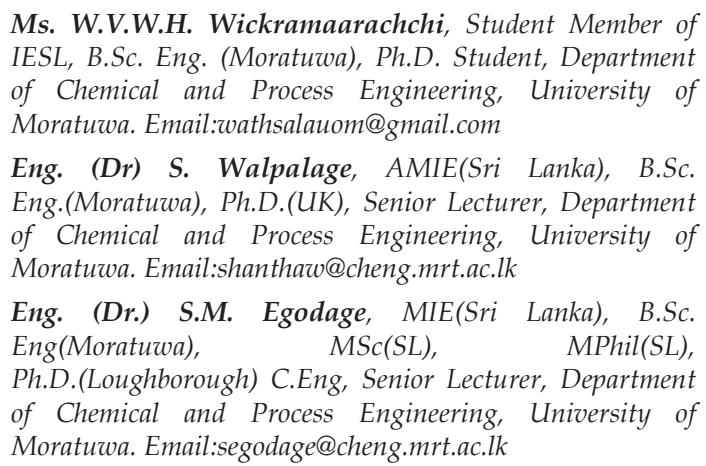


polyethylene can be used as raw material in producing roofing material, it may reduce its quantity. Though NR possesses excellent rubbery properties, due to its low chemical and weather resistance, use of NR is still confined to only a limited number of products. Furthermore, NR cannot be used alone in outdoor applications requiring a long service life. On the other hand, PE is significantly chemically inert and is alreday being used in roofing applications [5]. However, PE is of light weight and it is not possible to add more fillers to it in order to produce a cost competitive material. Therefore, blending of these two polymers may give the properties desirable for a roofing material.

The development of a roofing material using NR and PE will be highly beneficial to Sri Lanka, as it is a value-addition to raw rubber exports as well as an alternative roofing material which is cost effectitive, especially as a replacment to asbestoes.

\section{Experimental Results}

\subsection{Materials}

Natural rubber (NR) of RSS Grade 2 and three types of polyethylene, namely High Density Polyethylene (HDPE), Low Density Polyethylene (LDPE) and Linear Low Density Polyethylene (LLDPE) were used as base polymers to prepare simple and reactive blends. The specific gravities of HDPE, LDPE and LLDPE are 0.949, 0.923 and 0.935, respectively. Dicumyl Peroxide (DCP) was used as the reactive agent. All these chemicals were of industrial grade and were obtained from Samson Compounds (Pvt) Ltd.

\subsection{Blend Preparation}

Three series of blends were prepared by melt blending of NR with HDPE, LDPE and LLDPE in a plasticorder mixer by varying its composition from 30 to $70 \mathrm{wt} \%$ at intervals of $10 \mathrm{wt} \%$.

To prepare simple blends, HDPE, LLDPE and LDPE were first melted in the plasticorder operated for 2 minutes at a rotor speed of 30 rpm at temperatures of $145{ }^{\circ} \mathrm{C}, 140{ }^{\circ} \mathrm{C}$ and 135 ${ }^{\circ} \mathrm{C}$, respectively. NR was cut into pieces of 5 $\mathrm{mm}$ sizes and then added to the molten polyethylene to be processed for another 10 minutes at a speed of $60 \mathrm{rpm}$. To prepare reactive blends, $0.5 \mathrm{phr}$ of DCP was added to the NR/PE mixes and processed for another 5 minutes.
2.3

Determination of Mechanical Properties

Test specimens for tensile test, tear test and hardness of different simple and reactive blends of NR/HDPE, NR/LDPE and NR/LLDPE were prepared according to ASTM Standard D3182-85, using an electrically heated hydraulic press operated at temperatures of 155 ${ }^{\circ} \mathrm{C}, 150{ }^{\circ} \mathrm{C}$ and $145^{\circ} \mathrm{C}$, respectively, each under a pressure of $5 \mathrm{MPa}$. Reactive blends of NR/HDPE, NR/LDPE and NR/LLDPE were pressed at temperatures of $160{ }^{\circ} \mathrm{C}, 155{ }^{\circ} \mathrm{C}$ and $150{ }^{\circ} \mathrm{C}$ respectively. Compression time for all blends was kept constant at 5 minutes. The moulds were cooled to $40{ }^{\circ} \mathrm{C}$ under the same pressure before the moulded sheets were removed from the moulds.

Tensile properties and tear strengths of the moulded blends were determined using a Hounsfield H10KT tensile tester as per ISO 37:2011 and ISO 34-1:2010 respectively. Dumbbell specimens and angle specimens were cut from $2 \mathrm{~mm}$ thick moulded sheets using a die cutter, to determine tensile properties and tear strengths respectively. Both tests were carried out at $28 \pm 2{ }^{\circ} \mathrm{C}$ under a strain rate of 50 $\mathrm{mm} / \mathrm{min}$. Extension was taken as the movement of the crosshead. Toughness is defined as the area under the tensile stressstrain curve for polymeric materials [6], and is determined by calculating the area under the curve using the Trapezoid Rule [7]. The hardness of moulded blends was determined using a Shore D durometer in accordance with ISO 868:2003.

All tests were done at the Chemical and Process Engineering Department, University of Moratuwa.

\subsection{Determination of Thermal Properties}

Thermal properties were determined in accordance with ISO 22768: 2006 and using a Differential Scanning Calorimeter (DSC) from TA Instruments, USA. A weight of approximately 5-10 $\mathrm{mg}$ of each blend was placed in a tzero pan and the test was run in a nitrogen environment maintained at a flow rate of $35 \mathrm{ml} / \mathrm{min}$ and at a heating rate of $3{ }^{\circ} \mathrm{C} / \mathrm{min}$ over a temperature range of -80 to $0{ }^{\circ} \mathrm{C}$ and at a heating rate of $10{ }^{\circ} \mathrm{C} / \mathrm{min}$ over a temperature range of 0 to $160{ }^{\circ} \mathrm{C}$. Glass transition temperature $\left(\mathrm{T}_{\mathrm{g}}\right)$ and melting points $\left(\mathrm{T}_{\mathrm{m}}\right)$ were obtained from the DSC curves. Degree of crystallinity was calculated using the expression, 
$\%$ crystallinity $=\frac{\Delta H}{\Delta H_{m}^{0}} \times 100 \%$

where $\Delta H$ is the heat of fusion and $\Delta H_{m}^{0}$ is the heat of fusion for $100 \%$ crystalline polyethylene. $\Delta H_{m}^{0}$ for HDPE, LLDPE and LDPE are taken as $288 \mathrm{~J} / \mathrm{g}, 290 \mathrm{~J} / \mathrm{g}$ and 293J/g respectively.

\subsection{Water Absorption}

A test specimen of each blend weighing approximately $1 \mathrm{~g}$ was immersed in a water bath at room temperature. The specimen was removed from the water bath after 24 hours and gently blotted with blotting paper to remove excess water on its surface. The weight of each swollen sample was recorded. The degree of water absorption $\left(S_{w}\right)$ was calculated using the expression,

$S_{w}=\frac{W_{2}-W_{1}}{W_{1}}$

where $W_{1}$ and $W_{2}$ are the weights of the sample before and after water absorption respectively.

\section{Results and Discussion}

\subsection{Mechanical Properties}

Figures 1 and 2 show the tensile strength variation against NR loading for simple and reactive blends of NR/LDPE, NR/LLDPE and NR/HDPE. Tensile strengths for both simple and reactive blends decrease with the increase in NR loading. For any particular NR loading, the highest tensile strength is shown for NR/HDPE blends, while the lowest is shown for NR/LDPE blends. NR/LLDPE blends show intermediate tensile strengths. The tensile strength of blends was lower than the tensile strength of their respective pure PE grade. Table 1 shows the variation of the degree of crystallinity for both simple and reactive blends. Crystallinity of all polyethylene grades were interrupted by the addition of NR. HDPE has a low degree of short chain branching and is of a closely packed crystalline structure and hence it shows a higher degree of crystallinity. LLDPE has a high degree of short chain branching and a linearly packed structure. Hence the degree of crystallinity of LLDPE is lower than that of HDPE but higher than that of LDPE. LDPE has high degrees of long and short chain branching and shows a more amorphous structure.
As NR loading is increased, the degree of crystallinity of both simple and reactive blends decrease. After a $50 \%$ loading of NR, both the degree of crystallinity and the tensile strength show a drastic reduction. This may be due to the phase change of NR from dispersed to continuous. In a lower loading of NR, the polyethylene phase may be continuous. There is a higher increase in tensile strength in reactive blends than in simple blends. DCP is a cross linking agent which cross links both NR and polyethylene phases. Generally, $4-5 \mathrm{phr}$ is needed for rubber compound vulcanization. However, a quantity as small as $0.5 \mathrm{phr}$ is sufficient for the cross linking of thermoplastic elastomers. Cross linking of HDPE and LLDPE is more difficult compared to LDPE, which has a high branching structure. In Figure 2, HDPE and LLDPE show a higher reduction of tensile strength after a 50\% NR loading. Therefore, cross linking of HDPE and LLDPE will not occur at higher loadings [8]. The reduction of the degree of crystallinity of reactive blends is higher than that of simple blends. The crystalline structure of polyethylene has been influenced by the cross linking of both NR and PE phases.

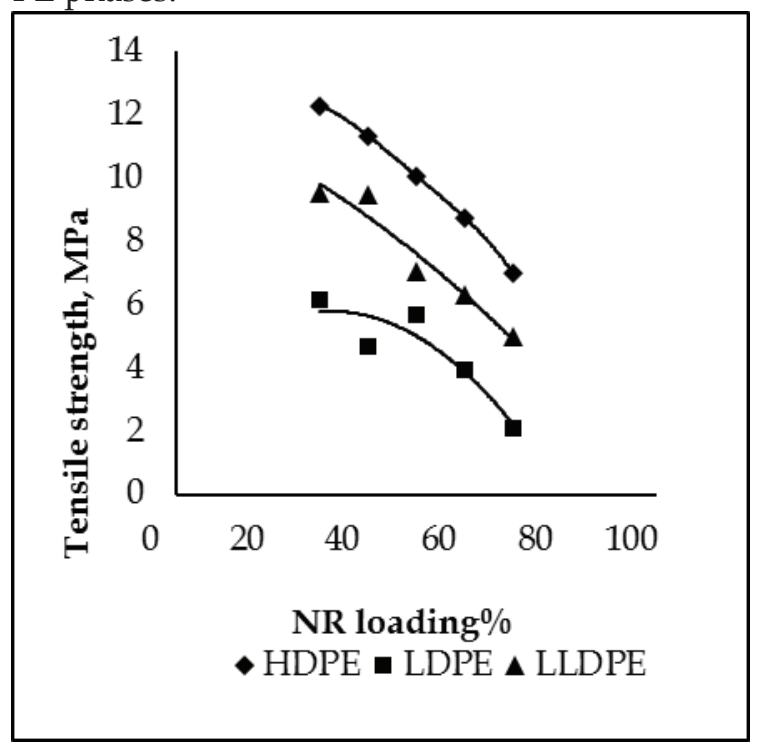

Figure 1 - Variation of tensile strength in simple blends

The tensile strength of all simple and reactive blends except simple blends of NR/LDPE at a $70 \%$ NR loading are higher than $3 \mathrm{MPa}$. Three $\mathrm{MPa}$ is the ultimate tensile strength of concrete, a brittle but versatile building material, and it is widely known that concrete based roofing tiles are of comparable strength. Therefore, a tensile strength of $3 \mathrm{MPa}$ was chosen as the minimum acceptable strength for roofing material [9]. 


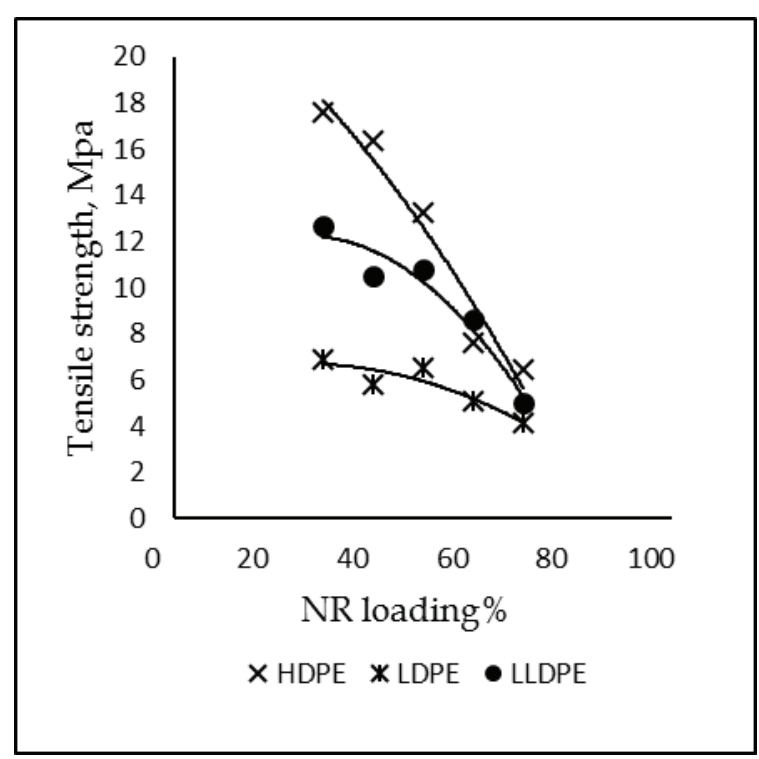

Figure 2 - Variation of tensile strength in reactive blends

Table 1 - Degree of crystallinity in simple and reactive blends

\begin{tabular}{llcc}
\hline Composition & $\begin{array}{l}\text { Pure } \\
\text { PE } \%\end{array}$ & $\begin{array}{l}\text { Simple } \\
\text { Blend } \%\end{array}$ & $\begin{array}{l}\text { Reactive } \\
\text { Blend } \%\end{array}$ \\
\hline NR/HDPE & $70-80$ & & \\
\hline $30 / 70$ & & 56.1 & 51.7 \\
\hline $40 / 60$ & & 54.6 & 45.1 \\
\hline $50 / 50$ & & 53.8 & 34.3 \\
\hline $60 / 40$ & & 24.2 & 25.4 \\
\hline $70 / 30$ & & 24.1 & 21.1 \\
\hline NR/LDPE & $45-55$ & & \\
\hline $30 / 70$ & & 35.5 & 30.6 \\
\hline $40 / 60$ & & 30.6 & 30.1 \\
\hline $50 / 50$ & & 26.3 & 26.1 \\
\hline $60 / 40$ & & 16.1 & 24.4 \\
\hline $70 / 30$ & & 13.8 & 10.7 \\
\hline NR/LLDPE & $60-70$ & & \\
\hline $30 / 70$ & & 27.4 & 28.3 \\
\hline $40 / 60$ & & 26.4 & 27.6 \\
\hline $50 / 50$ & & 21.5 & 19.6 \\
\hline $60 / 40$ & & 13.7 & 13.4 \\
\hline $70 / 30$ & & 11.9 & 8.8 \\
\hline
\end{tabular}

The variation of toughness of both simple and reactive blends is shown in Table 2. Generally, a high toughness is shown in 40/60 and 50/50 blends. Polyethylene is a ductile material with little toughness. Rubber, an energy absorbing material, has a toughness of approximately 10 $\mathrm{MJ} / \mathrm{m}^{3}$ [10]. Its toughness increases with the addition of NR up to $40-50 \mathrm{wt} \%$. The $30 / 70$ blends, due to their higher loading of polyethylene have less desirable ductile properties and hence their toughness is less. The toughness again decreases with NR loading when the NR phase becomes continuous.

Table 2 - Toughness in simple and reactive blends

\begin{tabular}{lcc}
\hline Composition & $\begin{array}{c}\text { Simple } \\
\text { Blend } \\
\left(\mathrm{MJ} / \mathrm{m}^{3}\right)\end{array}$ & $\begin{array}{c}\text { Reactive Blend } \\
\left(\mathrm{MJ} / \mathrm{m}^{3}\right)\end{array}$ \\
\hline NR/HDPE & & \\
\hline $30 / 70$ & 47.9 & 54.5 \\
\hline $40 / 60$ & 87.0 & 91.8 \\
\hline $50 / 50$ & 79.4 & 46.1 \\
\hline $60 / 40$ & 42.6 & 34.4 \\
\hline $70 / 30$ & 28.6 & 25.8 \\
\hline NR/LDPE & & \\
\hline $30 / 70$ & 37.5 & 28.8 \\
\hline $40 / 60$ & 44.7 & 32.5 \\
\hline $50 / 50$ & 38.2 & 31.4 \\
\hline $60 / 40$ & 37.6 & 22.5 \\
\hline $70 / 30$ & 37.3 & 8.7 \\
\hline NR/LLDPE & & \\
\hline $30 / 70$ & 60.3 & 70.8 \\
\hline $40 / 60$ & 96.2 & 94.9 \\
\hline $50 / 50$ & 39.9 & 76.6 \\
\hline $60 / 40$ & 44.9 & 45.4 \\
\hline $70 / 30$ & 35.5 & 11.9 \\
\hline & & \\
\hline
\end{tabular}

Table 3 - Hardness in simple and reactive blends

\begin{tabular}{|c|c|c|}
\hline Composition & $\begin{array}{l}\text { Simple } \\
\text { Blend } \\
\text { (Shore D) }\end{array}$ & $\begin{array}{l}\text { Reactive Blend } \\
\text { (Shore D) }\end{array}$ \\
\hline \multicolumn{3}{|l|}{ NR/HDPE } \\
\hline $30 / 70$ & 40 & 45 \\
\hline $40 / 60$ & 40 & 40 \\
\hline $50 / 50$ & 35 & 35 \\
\hline $60 / 40$ & 22 & 25 \\
\hline $70 / 30$ & 20 & 20 \\
\hline \multicolumn{3}{|l|}{ NR/LDPE } \\
\hline $30 / 70$ & 35 & 35 \\
\hline $40 / 60$ & 30 & 35 \\
\hline $50 / 50$ & 24 & 30 \\
\hline $60 / 40$ & 18 & 22 \\
\hline $70 / 30$ & 13 & 14 \\
\hline \multicolumn{3}{|l|}{ NR/LLDPE } \\
\hline $30 / 70$ & 35 & 38 \\
\hline $40 / 60$ & 22 & 35 \\
\hline $50 / 50$ & 26 & 32 \\
\hline $60 / 40$ & 20 & 25 \\
\hline $70 / 30$ & 15 & 18 \\
\hline \multicolumn{3}{|c|}{$\begin{array}{l}\text { In both simple and reactive blends, th } \\
\text { hardness gradually decreases as the NR loadin } \\
\text { is increased (Table } 3 \text { ). A NR/HDPE blend wil } \\
\text { have high rigidity than either a NR/LLDPE or }\end{array}$} \\
\hline
\end{tabular}


NR/LDPE blend. A NR/LLDPE blend when compared to a NR/LDPE blend has a higher hardness. Furthermore, reactive blends when compared to simple blends show higher hardness vales. This is associated with the cross linking of NR and/or polyethylene phases or with the formation of adhesions between the two phases.

Table 4 shows the variation of tear strength for both types of blends. Tear strength decreases for all blends as the NR loading increases. The highest tear strength was shown for the NR/HDPE blends. The NR/LLDPE (30/70) blend has a higher tear strength than the NR/LDPE of the same composition. After a NR loading of $40 \mathrm{wt} \%$, the tear strength of the NR/LDPE blend increases at a higher rate than that of NR/LLDPE blends. This may be due to the effective enhancement of the phase adhesion between NR and LDPE with the loading of DCP at $0.5 \mathrm{wt} \%$, and cross linking.

Table 4 - Tear strength in simple and reactive blends

\begin{tabular}{lcc}
\hline Composition & $\begin{array}{c}\text { Simple } \\
\text { Blend } \\
(\mathrm{kN} / \mathrm{m})\end{array}$ & $\begin{array}{c}\text { Reactive } \\
\text { Blend } \\
(\mathrm{kN} / \mathrm{m})\end{array}$ \\
\hline NR/HDPE & & \\
\hline $30 / 70$ & 96.57 & 102.7 \\
\hline $40 / 60$ & 83.71 & 88.5 \\
\hline $50 / 50$ & 69.38 & 71.7 \\
\hline $60 / 40$ & 46.35 & 56.3 \\
\hline $70 / 30$ & 31.67 & 42.32 \\
\hline NR/LDPE & & \\
\hline $30 / 70$ & 46.72 & 57.00 \\
\hline $40 / 60$ & 46.07 & 43.20 \\
\hline $50 / 50$ & 38.10 & 43.00 \\
\hline $60 / 40$ & 31.69 & 41.97 \\
\hline $70 / 30$ & 21.64 & 31.65 \\
\hline NR/LLDPE & & \\
\hline $30 / 70$ & 58.11 & 68.8 \\
\hline $40 / 60$ & 47.05 & 50.2 \\
\hline $50 / 50$ & 36.11 & 45.46 \\
\hline $60 / 40$ & 24.93 & 39.49 \\
\hline $70 / 30$ & 16.03 & 43.36 \\
\hline
\end{tabular}

\subsection{Thermal properties}

For pure PE and NR, Tg values are found to be $-125{ }^{\circ} \mathrm{C}$ and $-63{ }^{\circ} \mathrm{C}$ respectively. When NR is blended with $\mathrm{PE}, \mathrm{Tg}$ of both simple blends and reactive blends decrease to a value between -63 ${ }^{\circ} \mathrm{C}$ to $-65^{\circ} \mathrm{C}$. However, no significant variation is observed with an increase in NR loading.
$\mathrm{T}_{\mathrm{ms}}$ of simple blends do not vary with composition ratios. The slightly varied values of simple blends of HDPE, LDPE and LLDPE are generally similar to the melting temperatures of the respective virgin polyethylene grades. The variation of melting temperature of reactive blends has a trend similar to that of simple blends. However, melting temperatures have small increments of about $2^{\circ} \mathrm{C}$ in reactive blends when compared to respective simple blends. It may due to the vulcanization of rubber and polyethylene.

\subsection{Water absorption}

Table 5 - Water absorption in simple and reactive blends

\begin{tabular}{ccc}
\hline Composition & $\begin{array}{l}\text { Simple } \\
\text { Blend(\%) }\end{array}$ & $\begin{array}{c}\text { Reactive } \\
\text { Blend(\%) }\end{array}$ \\
\hline NR/HDPE & & \\
\hline $30 / 70$ & 0.2 & 0.11 \\
\hline $40 / 60$ & 0.2 & 0.20 \\
\hline $50 / 50$ & 0.39 & 0.10 \\
\hline $60 / 40$ & 0.43 & 0.28 \\
\hline $70 / 30$ & 0.51 & 0.31 \\
\hline NR/LDPE & & \\
\hline $30 / 70$ & 0.21 & 0.16 \\
\hline $40 / 60$ & 0.19 & 0.13 \\
\hline $50 / 50$ & 0.32 & 0.22 \\
\hline $60 / 40$ & 0.38 & 0.32 \\
\hline $70 / 30$ & 0.64 & 0.57 \\
\hline NR/LLDPE & & \\
\hline $30 / 70$ & 0.21 & 0.21 \\
\hline $40 / 60$ & 0.23 & 0.22 \\
\hline $50 / 50$ & 0.32 & 0.31 \\
\hline $60 / 40$ & 0.58 & 0.49 \\
\hline $70 / 30$ & 0.66 & 0.57 \\
\hline
\end{tabular}

The water absorption rate of natural rubber is normally higher than that of plastics. When polyethylene is introduced into a blend, it causes the blend to absorb less water. Furthermore, the degree of water absorption of reactive blends is slightly lower than that of simple blends (Table 5). The diffusion of water may be interrupted by the crosslink formation of the system. The maximum water absorption limit is varied according to the type of roofing material. In the Sri Lankan standards, it is stated that the water absorption of clay tiles, asbestos sheets and concrete tiles shall not be more than $18 \%, 28 \%$ and $10 \%$ of their dry mass respectively. 


\subsection{UV resistance}

Natural rubber has poor UV resistance while polyethylene has a fair degree of resistance to UV [11]. However, NR and polyethylene based products with UV absorbers are commonly used in outdoor applications such as bridge bearings, tyres, roofing materials, water tanks, etc. Hence NR/PE reactive blends could be developed with superior UV resistant properties.

\section{Conclusion}

Tensile strength, hardness, toughness and tear strength of simple and reactive blends of NR/HDPE always show higher values than those of NR/LDPE and NR/LLDPE blends for the same NR loading, while water absorption shows lower values. Therefore, from among HDPE, LDPE and LLDPE, HDPE may be the most suitable grade for NR/PE blends to be used as roofing material. Furthermore, the minimum acceptable tensile strength $(3 \mathrm{MPa})$ for roofing material can be obtained from reactive blends of all three grades of polyethylene and hence HDPE, LDPE and LLDPE can be used as roofing material after blending with NR. A high toughness was shown in the blend with a $40-50 \mathrm{wt} \%$ of NR loading. Toughness, an energy absorbing property, is most important for a roofing material to make it resist impact loads. Therefore, the most suitable blend compositions are $40-50 \mathrm{wt} \%$ of NR loading of all three grades of polyethylene. Physico-mechanical properties, UV resistance and other properties required of blends to be used as roofing material could be further enhanced with suitable additives.

\section{Acknowledgment}

This research project was supported by the National Research Council under the Public Private Partnership Programme (Grant Number PPP 14-08) between Chemical and Process Engineering Department; University of Moratuwa and Samson Compounds (Pvt) Ltd.

\section{References}

1. http://www.webmd.com/lung/asbestosexposure, Visited, 15th May 2016

2. Koning C., Van Duin M, Pagnoulle C., and Jerome R., "Strategies for Compatibilization of Polymer Blends," Prog. Polym. Sci., vol. 23, no. 4, pp. 707-757, 1998.

3. Naskar K., Rajesh Babu R, “Thermoplastic Elastomers (TPEs) and Thermoplastic Vulcanizates (TPVs)", pp 1-7 12 July 2014.

4. http://www.rrisl.lk/sub_pags/statistics.ht $\underline{\text { ml}}$, Visited, 15 th May 2016.

5. http://www.polyprofiles.co.za/diy.html, Visited, 15th May 2016

6. http://www.mathalino.com/reviewer/mec hanics-and-strength-of-materials/stressstrain-diagram, Visited 13 $3^{\text {th }}$ May 2016

7. http://people.stfx.ca/bliengme/exceltips/a reaundercurve.htm, Visited 13 th May 2016

8. Tamboli, S. M, Mhaske S. T, and Kale D. D., "Crosslinked Polyethylene", Indian Journal of Chemical Technology, vol 11, November 2004,pp. 853-864.

9. Bolaji A and Mosobalaje O. A," Development of a roofing material from polyrthylene through the use of additives", J.Mater.Civ.Eng.2008.20:516-520.

10. David Roylance, "STRESS-STRAIN CURVES", Department of Materials Science and Engineering, Massachusetts Institute of Technology, Cambridge, MA 02139, August 23, 2001

11. http://www.rtpcompany.com/technicalinfo/chemical-resistance/, Visited 2nd August 2016 